FACULDADE DE CIÊNCIAS ECONÔMICAS DA UFRGS
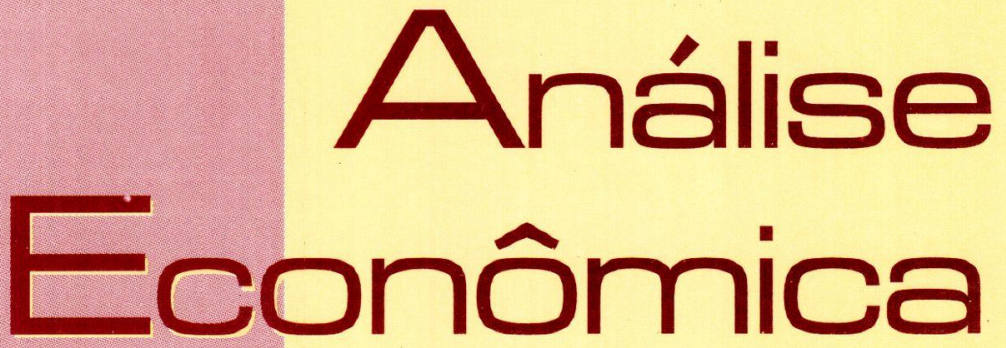

AS LOCOMOTIVAS ENFERRUIADAS

DO CAPITALISMO

Reinaldo Gonçalves

EFICIENNCIA, DESRECULAMENTACC̃O

FINANCEIRA E CRESCIMENTO

ECONOMICO: UMA ABORDAGEM

PÓS-KEYNESIANA

ROGÉRIO SOBREIRA

MERCADOS CONTESTÁVEIS E

COMPEIIÇÃO NO NOVO MODELO

DO SETOR ELÉtRICO BRASILEIRO

ELBIA VINHAES

EDVALDO SANTANa

MICROCRÉDITO: ASPECTOS TEÓRICOS

E EXPERIÊNCIAS

Márcio BobiK Braga

RUDINEI TONETO JR.

A RelaÇão Entre a Política e A ECONOMIA: SUAS IMPLICAÇÓES NO SISTEMA FINANCEIRO

JORGe PESSOA De MENDONĢA

AS RAiZzes CONCEITUAIS DO

INERCIALISMO

VAIDIR RAMAIHO

AUGE E INICIO DO DECLINIIO DA ECONOMIA ARGENTINA

maria Heló́sa lenz

$$
\text { ANO } \begin{array}{r}
18 \\
\text { No } 33
\end{array}
$$

MARÇO, 2000 
Universidade Federal do Rro Grande do Sui

Reitora: Prof ${ }^{a}$. Wrana Maria Panizzi

Faculdade de Ciências Econômicas

Diretora: Prof ${ }^{a}$ Otilia Beatriz Kroeff Carrion

Centro de Estudos e Pesquisas Econômicas

Diretor: Prof. Fernando Ferrari Filho

Departamento de Ciênctás Econòmicas

Chefe: Prof Luiz Alberto Oliveira Ribeiro de Miranda

Curso de Pós-Graduação em Economia

Coordenador: Prof. Marcelo Savino Portugal

Curso de Pós-Graduação em Economia Rural

Coordenador: Prof. Carlos Guilherme A. Mielitz Netto

Consel.ho Editorial:

Achyles B. Costa, Aray M. Feldens, Carlos A. Crusius, Carlos G. A. Mielitz Netto, Eduardo A. Maldonado Filho, Eduardo P. Ribeiro, Eugênio Lagemann, Fernando Ferrari Filho, Gentil Corazza, Marcelo S. Portugal, Nali I. Souza, Otnia B. K Carrion, Paulo A. Spohr, Paulo D. Waquil, Pedro C. D. Fonseca, Roberto C Moraes, Ronald Otto Hillbrecht, Stefano

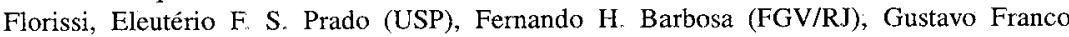
(PUC/RJ), João R. Sanson (UFSC), Joaquim P. Andrade (UnB), Juan H. Moldau (USP), Paul Davidson (Univ. of Tennessee), Werner Baer (Univ. of Illinois).

\section{Comissāo Entrorial:}

Eduardo Augusto Maldonado Filho, Fernando Ferrari Filho, Gentil Corazza, Marcelo Savino Portugal, Paulo Dabdab Waquil; Roberto Camps Moraes.

EorTor: Gentil Corazza

Edrror Adjunto: Pedro Silveira Bandeira

Secretário: Márcio Souza de Vargas

Revisão de Textos: Vanete Ricacheski

Fundador: Prof Antônio Carlos Santos Rosa

Os materiais publicados na revista Análise Econômica são da exclusiva responsabilidade dos autores. É permitida a reprodução total ou parcial dos trabalhos, desde que seja citada a fonte Aceita-se permuta com revistas congêneres. Aceitam-se, também, livros para divulgação, elaboração de resenhas e recensões. Toda correspondência, material para publicação (vide normas na terceira capa), assinaturas e permutas devem ser dirigidos ao seguinte destinatário:

PROF GENTIL CORAZZA

Revista Análise Econômica - Av. João Pessoa, 52

CEP 90040-000 PORTO ALEGRE - RS, BRASIL.

Telefones: (051) 316-3348 e 316-3440 - Fax: (051) 316-3990

E-mail: rae@vortex.ufrgs.br

Análise Econômica

Ano 18, $\mathrm{n}^{\circ} 33$, março, 2000 - Porto Alegre

Faculdade de Ciências Econômicas, UFRGS, 2000

Periodicidade semestral, março e setembro

1. Teoria Econômica - Desenvolvimento Regional -

Economia Agrícola - Pesquisa Teórica e Aplicada -

Periódicos. I. Brasil.

Faculdade de Ciências Econômicas,

Universidade Federal do Rio Grande do Sul. 


\section{Auge e início do declínio da economia argentina'}

Resumo: Este paper analisa o comportamento da economia argentina na sua fase inicial até o início do século XX e divide-se em quatro partes. A primeira apresenta uma periodização para as diversas fases da economia argentina. A segunda examina o período de formação da economia argentina, iniciando em 1820 e terminando ao redor de 1870 . A terceira, que inicia em 1870, examina o comportamento da economia argentina durante a chamada Belle Époque, especialmente em relação à influência inglesa, à constituição da base da economia do país com grande apropriação de terra para criação de gado, e à inauguração do primeiro frigorífico. A quarta examina a depressão econômica ocorrida em 1890/1900 e a crise bancária de 1890. Finalmente, a última parte apresenta uma discussão sobre o início do fim do período de rápido crescimento.

Palavras-chave: Economia argentina, desenvolvimento econômico, história econômica.

Abstract: This paper analyzes the performance of Argentina's economy from the early part until the begin of 20 th century. The first part present a periodization to Argentina's economy. The second part focus the the period from 1820 to 1870 . The third examines the Belle Époque itself, specially featured by the british influence, the constitution of the basis of the country's economy with great appropriation of land for cattle raising, and the creation of the first slaughterhouses. The fourth focuses on depression of 1890/1900 and the banking crisis of 1890 . The last focuses on the controversy on the end of the fast economic growth period.

Key-words: Argentina's economy, economic development, economic history.

\section{Introdução}

As histórias dos processos de desenvolvimento dos países latino-americanos foram profundamente marcadas pelo seu passado colonial, pelas relações entre as nações hegemônicas e esses países e pelo contexto econômico e político vigente ao longo do tempo.

\footnotetext{
' Artigo apresentado no III Encontro Nacional de Economia Política. Universidade Federal Fluminense Niterói. Junho de 1998.

* Economista da FEE, Professora Assistente da UFRGS e Doutoranda da UFRGS.
} 
$\mathrm{O}$ século XIX pode ser caracterizado como um marco de mudança em relação ao sistema de relações internacionais entre os países, pois, se por um lado, inaugurava o domínio do sistema anglo-saxão, significando a liderança da Grã-Bretanha com a defesa do livre comércio entre as nações, por outro, decretou a falência do modelo mercantilista europeu do século XIV, no qual Portugal e Espanha despontavam como os países mais importantes. Dentro desse cenário, dois países se destacaram como os principais protagonistas nos processos de desenvolvimento que marcaram a América Latina nos séculos XIX e XX: Brasil e Argentina. Evidentemente que esses processos foram diferenciados, a começar pelas próprias políticas de colonização espanhola e portuguesa que deram início ao processo e que marcaram profundamente as trajetória desses países, mas também guardam semelhanças extremamente importantes que merecem ser identificadas.

Este trabalho constitui-se na primeira parte de um estudo comparado sobre as raízes históricas dos processos de desenvolvimento econômico do Brasil e da Argentina. Ele tem como principal objetivo a tentativa de captar as trajetórias enfrentadas por esses países como forma de alcançar o desenvolvimento econômico nas suas caracterizações de países de desenvolvimento tardio. $\mathrm{O}$ estudo trabalha em várias frentes e matizes, partindo dos determinantes históricos que configuraram esses processos e englobando paulatinamente as relações internacionais, os condicionantes econômicos e sociais e os aspectos políticos, que influenciaram as trajetórias desses dois países. A parte referente ao estudo da economia argentina terá como início o fim do século XIX, mais precisamente o período que começa em 1870 e terminará na década de setenta do século XX, quando os modelos de industrialização adotados em todos os países latino-americanos entraram em um processo de estagnação.

Sem dúvida alguma, a história econômica da Argentina é um dos fenômenos mais fascinantes dentro da história econômica contemporânea. Nos dias de hoje, colocada na categoria dos países subdesenvolvidos e enfren" tando os mesmos problemas dos mesmos, a Argentina da virada do século era um dos países mais ricos do mundo, sendo posicionada ao lado das economias mais avançadas, tais como os Estados Unidos, o Canadá e a Austrália. Ao mesmo tempo, este país também experimentou um declínio econômico sem paralelo na maior parte do século XX. O declínio deste país uma vez desenvolvido no século XX constitui-se, segundo Días-Alejandro (1970, p. 230) “... em uma das mais enigmáticas e mal compreendidas histórias nacionais na literatura do desenvolvimento".

Dado o longo período a ser estudado dentro da história da economia argentina, optou-se, nesse trabalho, por examinar dois períodos: a fase ini- 
cial de formação da economia argentina e o período compreendido entre 1870 e 1914. Na verdade, o primeiro será visto apenas como uma forma de introduzir e entender o período mais importante: o que se inicia em 1870. A razão da importância do mesmo se deve a inúmeros fatores. Em primeiro lugar, por ser considerado dentro da literatura o início do período áureo dessa economia, também chamado de Belle Époque, além de se caracterizar pela chegada da Inglaterra, o país líder da economia mundial, e do início de sua enorme influência na economia argentina, que só termina no pós-guerra. Esse período também será o da constituição das bases da economia argentina, com grande apropriação de terras para a pecuária e a criação dos primeiros frigoríficos argentinos. Ele também marca o florescimento das atividades financeiras e bancárias no país, inclusive da ocorrência da primeira crise financeira argentina. Por último, este período foi extremamente importante na história argentina por ser o momento da consolidação do estado nacional.

É importante salientar que não existe grande controvérsia na literatura de que o ano de 1870 representa o início do período áureo do florescimento da economia argentina. Já o ano que marca o início da decadência da economia argentina, ou o fim do período de crescimento, é um ponto extremamente controverso. Alguns autores preferem datá-lo com o do início da Primeira Guerra Mundial - 1914 - e outros com o da Grande Depressão - 1929, e, outros ainda, com o da década de 1930. Nesse trabalho, optou-se encerrar o período de análise na eclosão da Primeira Guerra Mundial apenas como uma das possibilidades do marco da mudança e também por trazer para a discussão as outras posições que defendem periodizações diferentes para o início do declínio.

\section{As diversas fases do desenvolvimento da economia argentina}

$\mathrm{Na}$ bibliografia que trata das raízes do processo de industrialização argentino, destaca-se a obra de Ferrer (1995) por definir as fases históricas do processo de formação da economia argentina e também por adotar o mesmo de Furtado (1978) para o Brasil, o que possibilitará a posterior comparação entre os dois países. Para Ferrer existem quatro fases perfeitamente diferenciáveis no desenvolvimento econômico argentino. A primeira compreende o período entre o século XVI e final do século XVIII, sendo caracterizada pela existência de várias economias regionais de subsistência separadas umas das outras, produzindo basicamente para o consumo interno e com baixos níveis de produtividade. A segunda estende-se do fim do século XVIII até próximo de 1860, sendo definida como uma 
etapa de transição, durante a qual surge a atividade que vai ligar a Argentina ao mercado mundial: a produção de couros e de outros produtos ligados à criação de gado. Esse período também se notabilizou pela Declaração de Independência da Argentina e pelo aproveitamento da situação geográfica do Porto de Buenos Aires como pólo de integração do país aos mercados mundiais. A terceira, da economia primário-exportadora, inicia em 1870 com a incorporação da Argentina ao comércio internacional, sendo a mais fecunda, pois foi o período de crescimento da principal atividade que caracterizou o grande desenvolvimento argentino - exportação de carnes resfriadas, e também do desenvolvimento comercial e bancário e só termina com a crise de 1930. Além da expansão da atividade exportadora, essa etapa também caracterizou-se pelo intenso processo imigratório e pela entrada de capital estrangeiro na Argentina e da consolidação do estado nacional argentino.

A quarta e última etapa começa em 1930 e inaugurou a fase caracterizada por uma economia semi-industrial dependente, caráter derivado da insuficiente integração das diversas fases da produção manufatureira e dos altos preços relativos dos produtos industriais.

\section{Fase inicial da formação da economia argentina}

Conforme já foi ressaltado, elegeu-se para esse trabalho o exame do período 1870-1914 da história da economia argentina, em função de ter sido o mais rico, de crescimento mais intenso e também de ser aquele em que ocorreram as maiores transformações estruturais do país.

Mas para caracterizar-se essa etapa da história econômica argentina, é importante um breve resumo das principais características das fases anteriores.

A história propriamente dita da nação Argentina teve início no século XIX, mais precisamente no seu processo de independência de 1810 , ou 1816 , ano que declarou formalmente a sua independência, e se caracterizou por uma ruptura completa com a Espanha. É importante ressaltar que a Argentina era considerada uma zona estratégica na época em função de seus rios possibilitarem tanto o comércio de manufaturas como o de produtos coloniais. Em razão disso, a Inglaterra monitorou o desenvolvimento e a independência da Argentina fazendo alianças com o seu setor exportador hegemônico. Entretanto, apesar de ter forte interesse nas independências das colônias em função de seus mercados internos, não podia apoiar abertamente esses processos na América Latina, pois era aliada da Espanha e de Portugal nos conflitos europeus. Por isto, ela teve de deixar as elites locais fazerem esse jogo. 
A Grã-Bretanha teve, assim, grande influência nos conflitos dessa região por diversos motivos. Em primeiro lugar ela tinha interesse em impedir a formação de um grande país na Região do Prata, e jogou com a idéia de que, em 1815 na Europa, estava havendo o triunfo do conservadorismo e, na América, o do livre cambismo. Além disso, ela aproveitou o fato de a Europa estar em guerra e, em razão disso, Portugal e Espanha não poderem dar atenção as suas colônias. A Inglaterra mantinha seu poderio através da força de sua Marinha não sendo um império direto, exercendo sua preponderância através do domínio dos mares, sendo a sua principal atividade econômica o comércio internacional. É nesse sentido que o período que se situa no início do século XIX foi o da consolidação das novas nações e da hegemonia inglesa.

O Continente Sul-Americano foi um dos espaços mais importantes para o exercício dessa hegemonia. Boensner (1982) salienta que, a América Latina, logo depois da independência política formal, iniciou uma segunda etapa de dependência à Grã-Bretanha e secundariamente à França, assumindo o papel de sucessoras de Espanha e Portugal na hegemonia dos países latino-americano.

O que diferencia o poder hegemônico inglês dos poderes hegemônicos dos períodos anteriores é o fato de não ser mais baseado no controle territorial, mas sim em alianças com as oligarquias locais e no interesse da abertura dos mercados internos dos novos países. Para a Inglaterra, era importante a independência das colônias, mas não agrupadas, e também aproveitar para estabelecer o livre comércio com as mesmas, o que explica por que a principal preocupação dos ingleses era com a desembocadura dos rios da Região do Prata.

De acordo com Treber (1977), o domínio dos mares pela Inglaterra levou o país a estabelecer pontos estratégicos em todo o mundo e, assim, os investimentos ingleses nas Províncias Unidas del Rio de La Plata foram parte essencial dessa estratégia. A Argentina, local preferencial desses investimentos, passou a maximizar a utilização de sua terra. Primeiro esteve na produção de lã para atender a indústria têxtil, e depois evoluiu para a produção de carne e forrageiras, ante a crescente demanda interna por alimentos.

Esta fase inicial da formação das economias regionais de subsistência também contou com um fator que a diferencia das demais: a disponibilidade de mão-de-obra indígena. As atividades econômicas dinâmicas desta economia colonial foram aquelas estritamente ligadas ao comércio externo: a mineração, os cultivos tropicais, a pesca, a caça e a exploração florestal, atividades que atraíram capital e mão-de-obra. Por outro lado, as únicas atividades destinadas ao mercado interno, que se desenvolveram, foram aquelas que, de alguma forma, se vincularam ao centro dinâmico exportador: a produção de mulas no litoral e a produção de tecidos em Tucuman, 
ambas para as minas de Potosi no Peru. Durante todo este período, não houve, no atual território argentino, um mercado com um fluxo recíproco de capitais, mão-de-obra e produtos entre as regiões. A sua caracterização se dá pela existência de economias regionais auto-suficientes separadas por grandes distâncias, ausência de comunicações marítimas e/ou flụviais e precariedade dos meios de transporte terrestres. Cada economia regional era um sistema fechado e auto-suficiente, e a principal característica do desenvolvimento desse período foi a estagnação.

A etapa de transição, que cobre o fim do século XVIII até próximo de 1870 , trouxe a ruptura desse caráter fechado e auto-suficiente entre as regiões argentinas, provocada por dois fatores: o Porto de Buenos Aires, que possibilitou o comércio colonial com a Espanha através do Rio da Prata, e a importância da criação do gado no litoral como atividade para a exportação. Desponta, então, a importância de Buenos Aires, pois a sua posição estratégica assegurava a entrada de importações, proporcionando ao país o acesso de manufaturas baratas, e, ao mesmo tempo, possibilitava a exportação dos produtos nacionais originados da produção pecuária. Para o interior, entretanto, isto implicou uma lenta agonia, pois a entrada das manufaturas inglesas eliminou as expressões artesanais locais e a produção de gado tinha pouca possibilidade de competir com a existente na Província de Buenos Aires.

Identifica-se, assim, a influência do elemento dinâmico e característico desse período: o comércio externo. Segundo Ferrer (1995), o Porto de Buenos Aires teve uma importância decisiva na etapa de transição da economia argentina para a fase primário- exportadora. A produção de gado foi a primeira atividade importante na história econômica dessas economias regionais. O seu desenvolvimento no Litoral a partir do séc. XVIII constitui, junto com a abertura do Porto de Buenos Aires, o principal fator dinâmico do crescimento neste período.

Os fatores que facilitaram o desenvolvimento da criação de gado foram abundância de terras férteis na zona pampeira, expansão da demanda mundial, liberação do regime comercial, pouca complexidade das empresas de gado e a escassa necessidade de mão-de-obra nessa atividade. Em contraposição, existiam dois obstáculos para se alcançar o pleno desenvolvimento da pecuária: a expansão da fronteira e a elevação da produtividade na produção de gado.

Nessa fase, a posse da terra e o seu monopólio passaram a ser extremamente disputados por ser a terra a principal fonte de riqueza do país. Assim, no desenvolvimento argentino surge a figura do proprietário da terra e a do arrendatário, que efetua um pagamento a esse proprietário, a renda da terra, para a utilização desse meio de produção especial, não reprodutível que é a terra. A categoria renda da terra desempenhou um papel fundamental no 
desenvolvimento rural argentino e se caracterizou tanto como renda absoluta como diferencial. ${ }^{2}$

A renda de terra mais importante na Argentina foi a do tipo diferencial I e, ao atuar como multiplicador de sua magnitude, transformou-se em uma categoria-chave na questão de apropriação da terra. Segundo Laclau (1975, p. 37): “A magnitude da renda diferencial e o monopólio da terra constituíram-se em pauta e condição do crescimento ocorrido entre 1860 e 1930 . A expansão da renda determinou, assim, o crescimento próprio de um capitalismo dependente, com uma baixa taxa de inversão produtiva, mas com um sustentado aumento de consumo. Nessas condições, teve tendência a uma plena absorção de mão-de-obra, combinada com etapas de agudo desemprego estrutural."

O processo de expansão da fronteira na zona pampeira e a apropriação privada de novas terras ocupadas foram, por conseguinte, as mais importantes características da etapa de transição argentina e tiveram uma profunda influência na produção do conjunto do país. Surge a estância baseada no sistema de administração de uma grande propriedade e de trabalho assalariado.

No Litoral, a expansão das atividades comerciais e da pecuária, que tinham seus interesses estreitamente vinculados à expansão das exportações, incorporou ao seu processo de crescimento elementos dinâmicos que a distinguem das outras regiões. Uma característica importante do desenvolvimento do Litoral foi que, em razão das várias oportunidades disponíveis para o capital, houve uma difusão da acumulação em todos os setores econômicos da região. O comportamento do setor público também contribuiu significativamente para consolidar a expansão comercial da pecuária ao dar aos grupos dominantes o controle do recurso natural básico do Litoral: a pradaria do pampa.

Essa etapa cristalizou o regime de propriedade da terra que terá enorme influência nas etapas posteriores. A concentração da propriedade da terra constituiu-se em um dos fatores da concentração de renda do setor agropecuário, fixou o tipo de organização futura para as novas correntes migratórias e, principalmente, configurou uma estrutura social e política que condicionou todo o desenvolvimento argentino até os dias de hoje. De acordo com Oddone (1972, p. 12), "Em nenhum país da terra o processo de formação da classe proprietária de terra foi realizado com maior rapidez e com traços tão peculiares como entre nós".

Outra característica do período de transição foi a estagnação das exportações das províncias do interior, o que condicionou a própria estagnação

\footnotetext{
${ }^{2}$ Sobre o conceito teórico da categoria econômica renda da terra, consultar Lenz, Maria Heloisa $A$ Categoria Econômica Renda da Terra". Fundaçâo de Economia e Estatistica, Série Teses, 1, 1981.
} 
dessa, paralèlamente ao desenvồvimento da Província de Buenos Aires que detinha a atividade dinâmica fundamental - a criação de gado orientada para as exportações. A grande disparidade regional que se estabeleceu entre as duas regióes fez com que as províncias do interior tivessem a província de Buenos Aires como único canal para resolver os seus problemas. A independência do país colocou claramente essas questões, e a Província de Buenos Aires defendeu firmemente a sua autonomia sob a bandeira do federalismo. Manteve, desta forma, sua posição de privilégio e evitou que uma política de integração nacional criasse uma distribuição mais eqüitativa das receitas fiscais. Essa fase foi, portanto, marcada pela expansão do Litoral e pela subordinação definitiva do Interior. A introdução dos primeiros ovinos da raça merino, em 1826, aponta para o início de uma nova etapa da produção de gado do país. Isto porque a lã passa a se constituir em uma matéria-prima das mais demandadas e a idéia é, pela primeira vez, inserir a produção pecuária nas demandas das potências poderosas da época. Assim, o começo da criação de ovelhas e a subseqüente exportação de lã foi uma resposta à maior demanda da França e dos Estados Unidos. A primeira conseqüência dessa produção foi o aumento da demanda por terra, uma vez que ela exigia um uso mais intensivo de terra, mão-de-obra e capital.

Entretanto, como a zona temperada em que o merino poderia desenvolver-se coincide com aquelas que naquele momento estavam ocupadas pela produção do gado, simbolizadas pelas estâncias, sendo inevitável o choque desses interesses opostos que procuravam o seu recíproco deslocamento.

Deste modo em 1870, estavam dadas as condições para o início do terceiro período, sem dúvida, o mais importante da história da Argentina.

\section{Período áureo da economia argentina - a Belle Époque}

Apesar de todas as transformações dos períodos anteriores, a Argentina de 1870 ainda constituía-se em um país basicamente de economia pecuária com grandes extensões de terra para serem apropriadas. A população e 0 capital do país ainda eram escassos, e também eram poucas as estradas de ferro e as instalações portuárias. Segundo Levene (1956, p. 390), “... pelos cálculos de Martín de Moussy, os 44 mil habitantes existentes na Argentina em 1810, passaram a aproximadamente 2 milhões em 1870, segundo o censo do ano anterior".

A principal explicação da maioria dos autores para o extraordinário crescimento da economia da Argentina entre 1870 e 1914 - taxa de cresci- 
mento médio anual de $5 \%$ - é de que ele decorreu de importantes mudanças no comércio internacional. Segundo Conde (1991), a redução dos custos de transporte marítimo foi o fator mais importante, seguido pelo movimento dos fatores de produção capital e mão-de-obra entre os continentes. Para o autor, o exame desse processo apenas pelo lado da demanda internacional não reflete, porém, toda a riqueza e complexidade deste processo histórico, o qual teve outras facetas menos óbvias. O outro lado da explicação refere-se à necessidade de ajustamento do lado da oferta para responder aos aumentos reais ou potenciais da demanda mundial. Esse ajuste do lado da oferta constituiu principalmente na reorganização dessa economia primária. Foi necessário reorganizar a produção para obter mais produtos básicos - cereais e carne - através dos fatores de produção terra, mão-de-obra e capital.

Cabe lembrar que esse período, ao estruturar-se e consolidar-se na Argentina o sistema oligárquico - entendido como a aliança de interesses entre os latifundiários, comerciantes, políticos, militares e representantes do capital estrangeiro, basicamente britânico, também representa a constituição do Estado Argentino. ${ }^{3}$

A nova fase da economia primário-exportadora argentina, que inaugurou-se em 1870, pode ser sumarizada, portanto, em dois fatores: 1) expansão e integração crescente na economia mundial; 2) grande expansão das terras férteis, com baixa população, na zona pampeira. O primeiro refere-se à importância do progresso técnico como determinante da integração da Argentina na economia mundial. Pode ser desdobrado em fluxo de capitais, migrações e expansão comercial. A Argentina, nesse sentido, constituiu-se no caso mais significativo de um país integrado à economia mundial, pois este período marcou o aumento vigoroso das suas exportações e ela passou a deter um lugar de destaque nos mercados internacionais, tanto pelo volume de seu comércio exterior, quanto pela magnitude dos capitais estrangeiros nela investidos. A respeito disso, Halperin Donghi (1982, p. 181) afirma que: "a hegemonia dos operadores econômicos ligados à finança ultramarina constitui o aspecto mais relevante do desenvolvimento da cultura dos cereais". O segundo fator foi a chamada

\footnotetext{
${ }^{3}$ Sobre a questão da formação do estado nacional nessa época, é importante destacar a posição de Buchbinder (1994, p. 32), para quem toda a historiografia do século XIX preocupava-se em justificar a existência de naçôes preexistentes, anteriores a esse período. Ele faz referência aos autores Mitre e Lopes como os divulgadores da idéia que a nação argentina se encontrava prefigurada desde os tempos coloniais e "preexistia" nos estados provinciais. Embora o conjunto dessa obra tenha sido questionado em muitos aspectos essa idéia de nação preexistente foi disseminada pela maioria dos trabalhos. Constituiu também um argumento de primeira ordem nos debates sobre federalismo e sobre a intervenção do poder central nas províncias.
} 
"Campanha do Deserto", quando foram incorporadas para o cultivo novas e importantes zonas de grande fertilidade, que foram determinantes nessa nova etapa do desenvolvimento. ${ }^{4}$

Por sua vez, o crescimento das exportações foi condicionado por dois fatores: o aumento da demanda mundial para produtos agropecuários de clima temperados, e a disponibilidade de terras férteis na zona pampeira, não exploradas ou parcialmente utilizadas. ${ }^{5}$

Em relação ao aumento da demanda internacional, é curioso observar que na Argentina aconteceu um processo diferente do que normalmente se aprende em teoria do comércio internacional. Isto porque, no período que inicia em 1870 , não houve um aumento dos preços mundiais agropecuários que beneficiasse a Argentina, mas, ao contrário, esse foi um período em que os preços mundiais da produção agropecuária diminuíram.

A Argentina para poder competir passou a incorporar imensas extensões de terra em vista da necessidade de buscar novos pastos. É importante lembrar que a característica principal da criação de gado é que ela produz tanto bens de consumo como de capital. Segundo Conde (199l), a incorporação de novas terras com baixo custo teve como efeito o incremento dos rebanhos e a expansão da produção a um custo mínimo, compensando, assim, a baixa de preços e mantendo a rentabilidade da criação de gado. Cabe observar que a expansão territorial além de melhorar a atividade econômica também possibilitou a ocupação militar de novos territórios.

Nessa época, as estradas de ferro não explicam a expansão para as terras das novas regiões. Ao contrário, a expansão da agricultura, no final do decênio 1880 e durante 1890 , ligada diretamente à produção do trigo, deu-se primeiro em Santa Fé. Somente a produção que se estenderá pela Província de Buenos Aires a partir de 1895 é que esteve ligada diretamente ao crescimento da rede ferroviária. Entre 1888 a 1895 , as zonas cultivadas passaram de 2,5 mil para 5 mil hectares. A expansão mais notável deu-se em Santa Fé, com propriedades menores predominantemente ocupadas por proprietários. Ocorre também nova expansão agrícola em terras que haviam sido total ou parcialmente dedicadas à pecuária, existindo uma complementaridade entre a agricultura e a criação de gado. A instalação do primeiro frigorífico na cidade de Campanha em 1882 constitui um símbolo de um

\footnotetext{
${ }^{4}$ Sobre a Campanha do Deserto, Botana (1980, p. 111) afirma que: "Em abril de 1879, Roca marchou à frente do Exército Nacional na Campanha do Deserto. O êxito coroou a eficiência de uma empresa que contrastava com a estratégia defensiva na que se esgotou a guerra contra os índios durante quase duas décadas".

${ }^{5}$ De acordo com Geller (1975), o crescimento global das exportações é um fenômeno que ocorre quando culmina a organização definitiva do país; a expansão da fronteira agropecuária é um processo concomitante, ainda que não paralelo, ao crescimento das exportações
} 
novo período. Nesse ano aconteceu, também, o primeiro embarque de carne ovina para o Reino Unido.

Outro fenômeno dessa época foi o incremento do número dos arrendatários, havendo seu número elevado influenciado enormemente a formação de um panorama comum da historiografia argentina. Sobre isto, Scobie (1964, p. 5) afirma: "Aqueles cujos antepassados haviam podido adquirir e conservar enormes concessões de terra ou que agora obtiveram estâncias desfrutaram de uma existência dourada [...]. O capital britânico havia construído as estradas de ferro [...]. Quem já possuía terra, poder ou dinheiro monopolizava a riqueza que agora se obtinha nos pampas". Não havia nenhum recurso ilimitado, nem uma demanda insatisfeita de terra e o sistema de arrendamento não obstaculizava o acesso à propriedade da terra, pois com ele se obtinha maior rendimento. Por outro lado, a concentração de propriedade de terra em poucas mãos constituiu uma força política com uma poderosa influência na vida nacional.

A integração da Província de Buenos Aires à economia nacional foi solucionada pelo incentivo aos fluxos migratórios e à construção das estradas de ferro, viabilizada por capitais ingleses.

O período compreendido entre $1860-80$ teve como principal característica a adoção de uma ampla política de colonização. Na verdade, a escassez de mão-de-obra na Argentina foi um problema persistente durante todo o século XIX. As primeiras idéias de imigração na Argentina foram expressas por Rivadávia, em 1820, mas só foram efetivamente implementadas com sucesso após 1870 , pois políticos como Rosa tinham pouco interesse em projetos de imigração. Entre 1870 e 1914, chegaram à Argentina quase 6 milhões de imigrantes, principalmente homens jovens, espanhóis e italianos, sendo que em 1914, os estrangeiros superaram o número de argentinos de nascimento no grupo de 20 a 40 anos. Isto explica porque a influência dos imigrantes na força de trabalho total foi maior do que na população em geral. Houve duas influências da imigração na formação da força de trabalho: primeiro, seu aporte direto do crescimento da população total e no incremento da taxa de crescimento natural da população; segundo seu aporte anual de mão-de-obra que entrou no mercado de trabalho. Sobre a magnitude da imigração na Argentina, Oddone (1972. p. 13) afirma: "Nunca entrou em um país uma imigração tão proporcionalmente grande em um período tão breve".

Parte da mão-de-obra que entrava no país dirigia-se para o setor agrícola que, com o aumento da extensão de terra cultivada, seguiu aumentando durante todo o período, inclusive durante a crise de 1890. Isto aliviou o problema da falta de emprego e impediu que se agravasse. Quando a atividade econômica melhorou depois de 1900, houve novamente a resposta imediata do incremento da imigração. 
$O$ aumento de riqueza na Argentina entre 1870-1914 não beneficiou igualmente a todos os setores da sociedade. Dessa forma, os proprietários de terra foram os maiores beneficiados, sendo a pobreza dós imigrantes um problema adicional, que teve relação com o aumento no custo de vida.

Este período também reflete a formação do capital argentino e de um grande volume de empréstimos e investimentos externos provenientes da Inglaterra, primordialmente para a construção de estradas de ferro.

Evidentemente numa economia tão primitiva, como a da Argentina na época, o capital era escasso, sendo a riqueza da população constituída de terra e gado. As instituições eram poucas, havendo a necessidade crítica de investimento em infra-estrutura. Numa economia nova e rural e também orientada para exportações de produtos, os transportes por terra e por mar eram absolutamente indispensáveis. Beyhaut (1984) enfatiza que na Argentina existia, anteriormente, um sistema de comunicações pouco vertebrado em que caravanas de carretas desempenhavam o papel principal, enquanto subsistiam as economias regionais. As ferrovias construídas, predominantemente com capitais ingleses vindo para a Argentina após 1860, correspondem ao rompimento desse sistema, alterando a relação dessas regiões em benefício das províncias de Buenos Aires, Santa Fé e Entre Rios e o desmembramento de Catamarca e de todo o noroeste argentino. O sistema de estradas de ferro integrou-se, então, a um sistema dominado pelo capital estrangeiro que, por sua vez, assegurou altos fretes.

Mas foi o Estado que deu o ímpeto inicial, realizando endividamento externo com a Europa, sobretudo Inglaterra. Segundo Ferns (1965), citando Mulhall, do total de inversões do capital britânico na Argentina que chegava a 23,06 milhões de libras, $56,2 \%$ correspondiam a empréstimos ao governo e $28,6 \%$, a estradas de ferro. Isto explica porque os fundos originados neste período foram destinados à extensão de estradas de ferro com fins promocionais da atividade estatal, com proporções semelhantes aos investimentos diretos estrangeiros. $\mathrm{O}$ aumento surpreendente das estradas de ferro faz com que o período seja chamado de infierno ferroviário sendo que $3 / 4$ de sua rede se ligam à região pampeira. Ao difundir-se a produção agrícola no litoral pampeano, nas últimas décadas do século XIX e ao produzir-se, por conseguinte, o ingresso dos imigrantes na vida rural, as relações salariais se generalizaram, apagando os resíduos pré-capitalistas que ainda podiam resistir. Se a isto se somar a Conquista do Deserto, que eliminou a possibilidade de continuação da existência de uma população não integrada ao sistema, aceita-se que, no início do século XX, imperava no campo argentino um modo de produção claramente capitalista, Laclau (1975, p. 35).

Nessa época houve a criação dos principais bancos na Argentina: o Banco Província de Buenos Aires em 1854 e Banco Nacional em 1880. O 
principal interesse das operações bancárias privadas ou estrangeiras foi o comércio, principalmente com o do exterior, pois essas operações configuravam-se mais rentáveis e seguras. Além disso, o setor rural tinha outras alternativas como os bancos hipotecários e provinciais, que concediam os créditos para colheita, cercamento dos campos e o desenvolvimento do pedigree dos rebanhos. É importante salientar que não se pode dizer que a formação de capital argentino se deu no exterior. Nesse período, sem dúvida, houve a melhoria das terras, das ferrovias, do maquinário agrícola e do gado, ou seja, do total do capital argentino.

O período de 1900-14 constitui a "idade de ouro da indústria frigorífica" e será marcado pelo investimento em novos frigoríficos, a vinda de novas ondas de imigrantes, novas extensões de estradas de ferro e a agregação de novas terras para a produção de gado. Sem dúvida houve a tentativa de formatar o país para ser eternamente o granadero del mundo.

\section{A depressão de 1890/1900 e a primeira crise bancária da economia argentina}

O autor Conde (1991) dividiu o período analisado em dois: o de 18901900 para trazer uma das maiores peculiaridades dessa fase do desenvolvimento argentino, a chamada grande depressão de origem financeira que comprometeu enormemente o desempenho argentino; e o de 1900-1912 que apresentou novamente uma grande expansão econômica.

O subperíodo de 1890-1900 é o que mais interessa, pois foi o da ocorrência da primeira crise bancária da economia argentina. É importante salientar que, na Argentina, diferentemente dos Estados Unidos, o governo não respaldava todos os papéis financeiros em circulação. A grande prosperidade do período anterior foi apoiada na abundância de empréstimos externos que resultou, em 1890, em uma dívida externa de 300 mil libras. A crise iniciou em 1890 quando Londres não permitiu o adiamento dos pagamentos da dívida e nem a continuidade da transferência trimestral de fundos para a Argentina.

Segundo Martí (1983), para entender a crise é necessário conhecer o mecanismo desses empréstimos. A maioria dos empréstimos que os governos e as empresas argentinos obtinha no exterior em forma de empréstimos era a juros fixos, e por conseguinte implicavam o pagamento imediato de um serviço estipulado a ouro. De 1886 a 1890, a Argentina havia tomado emprestado aproximadamente 668 milhões de pesos ouro e o seu passivo, em 1892, montava em 922545000 pesos ouro. Enquanto os fundos do exterior continuaram afluentes, não houve problemas no balanço de paga- 
mento; quer dizer, o país obtinha as divisas necessárias para fazer frente ao pagamento dos serviços da dívida externa e da manutenção do nível de consumo de artigos importados. Deste modo, a crise aconteceu porque os fundos estrangeiros diminuíram antes que o valor das exportações se houvesse expandido, a ponto de cobrir os serviços da dívida e manter um nível de importações politicamente tolerável. Por outro lado, os projetos financiados pelos empréstimos estrangeiros, principalmente a construção de estradas de ferro e o melhoramento das terras, promoveram uma produção crescente de bens exportados, mas, devido a sua lenta maturação, não conseguiram que o valor e o volume das exportações aumentassem no mesmo ritmo que $o$ montante dos juros da dívida. Assim, segundo o autor, "a crise sobreveio quando houve a interrupção dos empréstimos que eram respaldados em ouro, provocou uma depreciação monetária e ao mesmo tempo o crack do sistema bancário". (Martí, 1983, p. 937).

Houve a quebra dos dois principais bancos argentinos e alguns provinciais. A crise só começará a ser revertida quando, devido a novas negociações em Londres, foi liberado um empréstimo de 15 milhões de libras para o país. Essa crise, que entrou na literatura como a "crise do Baring", em razão desse tradicional banco inglês constituir-se no maior credor da dívida argentina, foi extremamente traumática, gerando grandes perdas econômicas. $\mathrm{Na}$ opinião de Ford (1975, p. 119), essa crise não foi apenas uma crise bancária, mas sim uma crise de desenvolvimento, de esgotamento do modelo vigente extremamente dependente de recursos externos. Segundo ele, isto não foi entendido por muitos autores que privilegiaram em suas explicações fatores como a corrupção e a desonestidade na Argentina entre as principais causas dessa crise.

A retomada do crescimento ocorreu no subperíodo 1900-1912 e teve como característica a propagação da produção do trigo por toda a Província de Buenos Aires, a retomada da construção de ferrovias interrompida durante a crise, as novas formas de congelamento e transporte da carne, e, na pecuária, o uso mais intensivo do fator trabalho, utilização de pastos artificiais e de plantação de forrageiras. Todas essas novas técnicas e mudanças geraram as seguintes conseqüências: em primeiro lugar, houve a criação de novos assentamentos de população em zona rural; em segundo, a criação de cidades e redes de transportes; em terceiro, o surgimento da figura, nessas regiões, do grande arrendatário; e, por último, a diminuição do número de estâncias pequenas e médias.

A criação de estradas de ferro teve efeitos diferentes na formação de mercados. Assim, restauraram-se antigos mercados regionais, mas agora vinculados à costa, formando um só mercado nacional. Os produtos se transportavam primeiro aos centros ferroviários que, devido a eles, converteram- 
se em mercados primários, e logo em mercados secundários da região costeira. As ferrovias enlaçavam os mercados do interior com os mercados urbanos da costa e, desta maneira, acabaram criando um mercado nacional. A criação desse mercado também teve como efeito o surgimento de indústrias, principalmente as de preparação de alimentos, têxtil e de bebidas. As regiões em que houve o maior desenvolvimento da indústria por capital investido foram Santa Fé (1895); Tucuman; Entre Rios; Mendonça e Córdoba (1912). Todas essas indústrias eram vinculadas ao setor agropecuário. Sobre isto, Dorfman (1942, p. 100) afirma que:

... fica comprovado que no fundamental a indústria argentina nasce estreitamente ligada ao campo, ligada quase por completo às atividades básicas que presidem o desenvolvimento da indústria nacional. Transformações de carnes e subprodutos, a produção do trigo, cana-de-açúcar e vinho; aqui temos as quatro gamas da atividade industrial que, em 1895, abarcavam a grande maioria de capitais nacionais.

O crescimento, que engloba todo o período analisado, além de caracterizar-se pelo aumento da riqueza e concentração de renda e propriedade, também marcou o início dos movimentos organizados. Em relação ao primeiro aspecto, Solberg (1975, p. 247-48) constata que "desde meados do século XIX, um grupo reduzido e fechado de famílias de classe alta era dono indiscutível de quase toda a terra fértil da zona de cereais. Na província de Buenos Aires, de importância fundamental, a estrutura de propriedade era característica: somente 1.041 estâncias ocupavam um terço da enorme superfície dessa província, incluindo grande parte das terras mais aptas para a criação de gado e cultivo. (...) na zona rica de Santa Fé, por exemplo, o preço das terras de cultivo subiu de de 60 pesos ouro por hectare em 1905 para 102,8 pesos ouro por hectare em $1912 " .{ }^{6}$

Quanto aos movimentos sociais, a primeira greve em grande escala que se registra na Argentina ocorreu em 1912 na cidade santafesina de Alcorta, centro de uma rica região produtora de milho, cujos colonos eram na maioria italianos. $O$ resultado significativo desse movimento foi a criação dã primeira e mais importante confederação de agricultores do país, a Federação Agrária Argentina (FAA). Segundo Solberg (1975, p. 252), esta organi-

${ }^{6}$ É interessante destacar a observação de Sábato (1988, p. 263) sobre isto. Para ele a concentração de riqueza e de poder se manifestava na visualização prematura de um grupo homogêneo, ainda que difuso, que detinha uma riqueza e um poder incomensuravelmente superior a todo outro grupo social da Argentina. Uma "oligarquia difícil de definir, mas fácil de identificar no seio da sociedade, em que em uma visão por demais simplista via apenas a existência de proprietário de terra, quando, na realidade, já havia a abertura de oportunidades para todas as atividades econômicas". 
zação se converteu principalmente em um grupo de pressão dedicado a proteger os interesses de seus membros, pequenos burgueses rurais.

$\mathrm{Na}$ história argentina, portanto, não existiram três décadas que tenham experimentado uma expansão econômica tão significativa como as que precederam a Primeira Guerra Mundial. A principal explicação, para Solberg, encontra-se na maior capacidade de adaptação das exportações argentinas. Durante 1875-79, as exportações argentinas ainda se constituíam de lãs, couros e carne salgada. Em 1890-94, o trigo converteu-se no produto predominante; em 1900-1904, tanto o milho como o linho tinham adquirido, cada um em separado, tanta importância quanto os couros; e, finalmente, no período 1910-1914, as exportações de carne congelada eram quase tão importantes quantos as de lãs. Também as atividades industriais progrediram durante o período 1880-1913, embora o setor manufatureiro continuasse apresentando lacunas expressivas. Era inegável a quase total dependência das importações para o suprimento das necessidades de máquinas e equipamentos do país; o mesmo sucedendo com os combustíveis. Inclusive os têxteis provinham principalmente do exterior, e, em 1913, a indústria têxtil argentina era menos importante que a do México e do Brasil. Mesmo assim: "Referindo-se ao período 1880-1913 os argentinos de 1913 bem podiam falar de um milagre argentino, de um despegue ou de um Grande Salto para Frente". Díaz-Alejandro (1980, p. 375).

\section{Discussão sobre o início do declínio do crescimento argentino}

O capital externo foi crucial no desenvolvimento da Argentina, tornando os fluxos internacionais vitais para o desenvolvimento dessa economia. Existem muitas explicações na literatura para a adoção desse modelo aberto, desde a visão de que esta escolha foi ditada pelas potências estrangeiras, dentro da visão da teoria da dependência, até para a inviabilidade desse modelo em razão da baixa capacidade de poupança interna do país em virtude do crescimento demográfico associado com a grande onda imigratória que teria dado uma estrutura populacional etária a Argentina de um grupo jovem não poupador. Sem querer entrar nessa polêmica ainda, a verdade é que a economia argentina floresceu durante o seu período áureo de crescimento quando os empréstimos externos, principalmente os do mercado financeiro de Londres, financiaram um crescimento rápido tanto do capital como do crescimento da renda, fazendo da Argentina uma das economias de crescimento mais rápido do mundo. 
A discussão sobre o início do declínio da economia argentina tem importância em razão das questões das políticas econômicas que acompanham os modelos e as soluções inerentes aos mesmos. Dentro disso, para Taylor (1992), o declínio da economia argentina começou em 1914, em virtude da ruptura dos créditos internacionais, seguindo no colapso do mercado internacional de capital e a retração da influência britânica. Isto teria causado um gap na balança de pagamento que já não poderia ser mais coberto por empréstimos financeiros e, a isto juntando-se, a carga demográfica de uma população jovem fez com que baixasse a taxa de acumulação de capital no período interguerras. Por este enfoque, a idéia do autor é de que, se a taxa de dependência dessa economia fosse mais baixa e mais próxima das demais economias coloniais, o desempenho da economia argentina poderia ser mais próximo do do resto do mundo. Nesta mesma linha, os autores Di Tella e Zymelman (1976) argumentam que a Argentina experimentou uma significante redução no crescimento econômico depois de I Guerra Mundial. Segundo eles, houve inclusive "um grande atraso" entre 1914 a 1933, que eles atribuem a políticas econômicas mal orientadas. Ao defender essa hipótese do início do declínio em, 1914 os autores, além das políticas econômicas, evocam o fechamento das fronteiras, entendendo que a região fértil dos pampas já estava plenamente ocupada nesse período. Na mesma direção, Conde (1994) refez as estimativas do Produto Interno Bruto da economia argentina para o período $1875-1953$ e constatou que o mesmo cresceu a uma taxa média anual de $8,3 \%$ entre $1900-13$ e uma taxa muito mais baixa de $4,3 \%$ no período $1917-29$.

Defendendo posição contrária Días-Alejandro (1975) argumenta que a performance da economia argentina no século XX foi de crescimento continuado e forte até os anos 20 , apesar de concordar com o fechamento da fronteira. Ele mostra que, considerando a quebra associada à Primeira Guerra Mundial como compreensível e temporária, a Argentina foi bem nesse período, quando comparada com países como a Austrália e o Canadá. Segundo esse autor, a Primeira Guerra Mundial deixou a Argentina convalescente, mas ainda firmemente integrada ao mercado financeiro mundial sem necessidade de trocas drásticas nas relações com o capital externo até a Grande Depressão de 1929. O seu argumento está na mesma linha da de Prebich (1929), que argumenta que a atividade da economia argentina no final dos anos 20 excedeu o período pré-guerra.

Toda esta discussão mostra que ainda existe muito a ser investigado a respeito do fim do período de crescimento intenso argentino, assim como aprofundar mais o estudo do mesmo, o que será objeto de outros trabalhos. 


\section{Conclưsão}

À guisa de conclusão, cabe apenas salientar que o período analisado da história da economia argentina, 1870-1914, não foi somente o de maior crescimento econômico, a uma taxa média anual de $5 \%$, mas sim o mais importante de sua história, com mudanças importantes que modificaram significativamente o caráter de sua economia.

Em 1910, ao comemorar o seu centenário de independência, a Argentina havia se convertido no país periférico que mais progresso tinha realizado e que ostentava os índices de crescimentos mais altos do mundo. $O$ projeto nacional da Constituição de 1853 podia ser visualizado no imenso desenvolvimento das estradas de ferro, no desembarque de imigrantes, e no progresso agrário. Para Paradiso (1996, p. 15), “... o processo de organização nacional se fortaleceu junto com a consolidação do modelo de um país aberto ao mundo que edificou seu notável ciclo de expansão econômica sobre a base do intercâmbio de produtos alimentícios da pampa úmida por produtos manufaturados e capitais emigrantes".

Às vésperas da Primeira Guerra Mundial, a Argentina tinha deixado de ser um país relativamente atrasado para se transformar em um país moderno, com uma imensa população rural e uma extensa rede ferroviária de $43.000 \mathrm{Km}$. Esse crescimento também motivou a aparição da indústria nacional de construção, alimentação, bebidas e têxtil. A redução dos fretes marítimos, o desenvolvimento da indústria doméstica, o grande movimento de capitais e a imigração foram fatores decisivos.

A Argentina no início do século XX constituía-se no principal país exportador mundial de produtos alimentícios e tinha desfrutado quase 35 anos de crescimento econômico. Esse desempenho esteve sempre ligado ao aspecto externo: impulso externo, mão-de-obra e capital estrangeiros e capital e mercado externo.

Nos anos 20, quando as condições externas se modificaram, pondo fim a entrada de imigrantes e de capitais estrangeiros no país, a economia argentina já estava mostrando sinais de saturação em relação a sua capacidade de absorver recursos externos, como também que era extremamente dificil substituir a economia primária exportadora. A Argentina era ainda uma sociedade mista e complexa, com regiões modernas coexistindo com superatrasadas. O potencial de seu crescimento estava diminuindo, e, em vez de continuidade de crescimento, começou uma seqüência de auges e depressões.

Ao contrário da grande maioria de outros países da América Latina, a Argentina, já na metade dos anos vinte, começou a formular um modelo alternativo ao vigente, já visivelmente esgotado, com a tendência de operar 
a substituição das exportações nas atividades de menor valor agregado, ou de procedimentos menos sofisticados, com o objetivo de atender ao mercado interno. No caso argentino, este novo modelo, teve de conciliar uma série de obstáculos e inconvenientes: a rigidez da infra-estrutura criada anteriormente, a deformação operada em relação à localização espacial e, muito especialmente, os interesses nem sempre coincidentes de uma poderosa oligarquia proprietária de terras. Muito já se escreveu sobre a questão da dependência da economia argentina, também questionando sobre se os modelos de substituição de importação teriam sido a escolha correta, o modelo alternativo para livrá-la dessa dependência e para a superação das dificuldades vigentes, mas está é uma discussão posterior a este período.

Finalmente, o traço característico da economia argentina após o seu período áureo, em que pese a correção ou não das decisões de política econômica, será o seu distanciamento das taxas de crescimento das economias desenvolvidas e a sua aproximação com as das economias latino-americanas e de uma sucessão de comportamentos irregulares com muitos componentes dramáticos.

\section{Referências bibliográficas}

BEYHAUT, Gustavo e Hélele. América Latina III. De La Independencia a la Segunda Guerra Mundial. México, Siglo XXI, 1985.

BOENSNER, C. Relações Internacionais da América Latina. Caracas, Ed. São José, 1982.

BOTANA, Natalio La Reforma Politica de 1912. Barcelona, Editorial Crítico, 1980.

BUCHBINDER, P. La Historiografia Rioplatense y el Problema da las Orígenes de la Nación. Cuadernos del CLAEH, n 69. Montevideo, 2 série, año 19. 1994/1.

CONDE, R. El Crescimento de la Economía Argentina (1970-1914). in BETHELL, Leslie. (ed) História da América Latina. 10 América de Sur. 1870-1930. Barcelona: Editorial Crítico, 1991.

CONDE, R. Patrones de Asentamiento y Explotacion Agropecuaria en los Nuevos Territorios Argentinos ( 1890-1910) en Álvaro Jara ed, Tierras Nuevas, México, 1969.

CONDE, R El Progresso Argentino, 1880-1914, Editorial, Buenos Aires, 1979.

-- Tierras, Agricultura y Ganaderia. In GUSTAVO FERRARI e EZEQUIEL GALLO (copiladores). La Argentina del Ochenta Al Centenario, Buenos Aires, Editorial Sudamericana, 1980.

DÍAS-ALEJANDRO, C. D. Essays on the Economic History of the Argentina. Republic, New Haven, 1970.

DI TELLA, Guido e ZYMELMAN, M. Las Etapas del Desarrollo Económico Argentino. EUDEBA, Buenos Aires, 1967. 
DORFMANN D. História da Industria Argentina, Buenos Aires, Alianza Editorial, 1942.

FERNS, H. S. Britain the Nineteenth Century, Oxford, Claredoon Press, 1960.

FERRER, Aldo. La Economia Argentina; las Etapas de su Desarrrolo y Problemas Actualles. Buenos Aires: Fundo de Cultura Economica, 1995.

FORD, G. La Argentina y la Crisis de Baring de 1890. In El Regime Oligárquico. Materiales para el estúdio de la realidade argentina (hasta 1930). Buenos Aires. Amorrortu Editores.1975.

FURTADO, Celso. Formação Econômica do Brasil. Nacional. Rio de Janeiro, 1878.

GELLER, Lucio E1 Crescimento Industrial Argentino hasta 1914 y la Teoría del Bien Primario Expotable. In El Regime Oligárquico. Materiales para el estúdio de la realidade argentina (hasta 1930). Buenos Aires. Amorrortu Editores.1975.

HALPERIN DONGHI, Tulio. História Contemporanea de America Latina. Alianza Editorial, Madrid, 1982.

LACLAU, E. Modos de Produção, Sistema Económicos y Población Excedente. In El Regime Oligárquico. Materiales para el Estúdio de la Realidade Argentina (hasta 1930). Buenos Aires. Amorrortu Editores.1975.

LEVENE, R. História da Nacion Argentina, Buenos Aires, Editorial Sudamericana, 1956.

MARTÍ, Geraldo Marcelo. Argentina; La Crisis de 1890. Endeudamiento Externo y Crack Financeiro. El Trimestre Economico. Fondo de Cultura Econômica, México, 1983.

ODDONE, Juan, El Tema de la Inmigración a través de los Archivos Italianos y Espanõles. In GALLO e FERRARI (copiladores). La Argentina del Ochenta al Centenario. Buenos Aires, Editorial Sudamericana, 1972.

ORTIZ, R. História Economica de la Argentina, 18.50-1930. Editorial, Buenos Aires, 1995.

PARADISO, José. El Poder de la Norma y la Política del Poder 1880-1916 in JALABE, Silvia. (org.) La Política Exterior Argentina y Sus protagonistas. Consejo Argentino para Las Relações Internacionais. Buenos Aires. Grupo Editor Latinoamericano, 1996.

SÁBATO, Jorge. La Classe Dominante en la Argentina Moderna-formación y características. Buenos Aires, CISEA. Grupo Editor Latinoamericano. 1988.

SCOBIE, J. Revolution on the Pampas: a Social History of Argentine Wheat, Austin, Texas, 1964.

SOLBERG, Carl. Descontentamento Rural y Política Rural en la Argentina, 19121930. In El Regime Oligárquico. Materiales para el Estúdio de la Realidade Argentina (hasta 1930). Buenos Aires. Amorrortu Editores. 1975.

TAYLOR, Alan, External Dependence, Demographic Burdens, and Argentine Economic Decline After the Belle Époque, in The Journal of Economic History, vol 52, 1992.

TREBER, Salvador. La Economia Argentina; Análisis, Diagnóstico y Alternativas. Buenos Aires: Macchi, 1977. 